\title{
MAKER: CAD + 3d Printing + Mold-Making: How to Create Custom Ster- ling Silver Pendants
}

\section{Ms. Lauren Jatana Vathje , University of Calgary}

Lauren is a mechanical engineering grad student whose research focuses on community engaged learning in engineering education. In addition to service learning, Lauren is inspired by creativity, design and the maker culture.

\section{Prof. Marjan Eggermont, University of Calgary}

Marjan Eggermont is the current Associate Dean (Student Affairs) and a Senior Instructor and a faculty member at the University of Calgary in the Mechanical and Manufacturing department of the Schulich School of Engineering, University of Calgary, Canada. She teaches graphical, written and oral communication in their first Engineering Design and Communication course taught to all 650 incoming engineering students. With co-editors Tom McKeag (San Francisco) and Norbert Hoeller (Toronto) she co-founded and designs $\mathrm{ZQ}$, an online journal to provide a platform to showcase the nexus of science and design using case studies, news and articles (zqjournal.org). As an instructor, she was one of the recipients of The Allan Blizzard Award, a Canadian national teaching award for collaborative projects that improve student learning in 2004. In 2005, she was one of the recipients of the American Society of Mechanical Engineers Curriculum Innovation Award. She is - as PIC II chair - currently a board member of ASEE.

\section{Dr. Bob Brennan, University of Calgary}




\section{MAKER: CAD + 3d Printing + Mold-Making: How to Create Custom Sterling Silver Pendants}

Introduction

Engineering education is indeed in a state of transformation towards emphasizing professional skills and holistic approaches to grand challenges of the world, but amongst this transformation engineering programs cannot let the emphasis on creating technically confident, problem solvers fade.

Maker projects reach to the core of engineering, and can prime students to construct better knowledge when subsequently exposed to traditional less active styles of learning (e.g. lecturing). Through the nature of the maker projects that combine inductive teaching methods with an ability to reach the intrinsic motivations of students, they not only promote technical fluency, but enhance the quality of learning and can also increase success in the workplace.

Prince and Felder ${ }^{1}$ describe inductive teaching methods as facilitated learning in a style that "induces students to construct knowledge for themselves, whenever adjusting or rejecting their prior beliefs and misconceptions in light of evidence provided by the experiences". Due to roots in constructivism, maker projects are the antithesis of lecture-based learning and work well with inductive teaching pedagogies. However, lecture based teaching is still the most widely used instructional method in post secondary institutions, but due to the passive nature of this style, the quality of learning in skills, such as critical thinking, has taken a traumatic fall. ${ }^{2}$ Exposure to an active maker style experience can be used to help students begin to construct meaning prior to a less active learning experience such as lecturing.

Maker projects can also be adapted to leverage intrinsic motivation of students. If a project is in the context of something a student sees as useful, then they are more likely to spend more time engaging in the learning activity ${ }^{3}$. For example, manufacturing processes like this mold-making project can be adapted to a wide variety of interest areas (i.e. jewelry making, custom chocolates, action figures etc.) that could evoke a genuine interest by students and thus engage them more.

No matter how many formulas or sketches a student does, there is a critical need to understand the nuances of working with physics and science in the real world. The tactile nature of maker projects enhances technical fluency. Analogous to learning how to speak a language, when one is working with their hands, they are learning to speak with the material, physics and natural laws. Additionally, research shows that knowledge transfer will be higher when the learning environment resembles the work environment. ${ }^{3}$ It is more likely that a maker stylemanufacturing project will be more representative of the work environment than textbook illustrations of the process. After all, engineering is often referred to as applied science.

The following maker project promotes technical fluency with manufacturing technologies. If students are exposed to maker style project like this one - the technical/tactile, leaner centered, motivated and inductive learning experience will prime students to construct and reconstruct 
stronger knowledge during the following learning experiences that may come in a less active form of teaching.

Maker Project Description: How to Create Custom Sterling Silver Pendants

There are many wonderful aspects to the Maker culture. Especially the fact that everyone is empowered to make almost any vision come to life; ideas no longer have to live in dreams and sketch books.

The maker-themed project we have pursued is the creation of sterling silver jewelry through $\mathrm{CAD}$, rapid prototyping, molding and casting. This project is for engineering students who find themselves missing hands on, creative and aesthetic projects.

The idea for this project came over the period of two years from an array of different maker themed events. From exposure to $3 \mathrm{~d}$ printers and precious metal clay (PMC) jewelry at the local maker fair, to workshops on molding/casting at the science center - the idea slowly came to life to combine these technologies to create hand made pieces of jewelry. The idea for the pendent must first be conceived, translated to CAD and then 3D printed. After filler is applied to the 3D print and it is polished - the model is ready to be made into a silicone mold. When the silicone mold has set, mold-release (or oil) is applied to the inside of the cavity (PMC is quite sticky) and is then pressed into the mold. After leaving the PMC to dry for half an hour or more, take out the hardened clay and put it into the mini-kiln for firing. Use a wire-brush to file the silver piece for a beautiful shine and then attach it to a chain to show it off.

The value of this project is that a jewelry project may bring more undergraduate women to maker spaces. Jewelry is a common conversation topic between women, which means projects like this will evoke more dialogue between about the amazing intersection of creativity, design and engineering processes. Of course, this opportunity provides engineering undergrads of all demographics the chance to work with their hands and exposure to methods and tools. One final benefit of maker projects in general is the inherent shift away from mindless consumerism due to the effort that is put into crafting our own possessions.

Maker Project Outline:

1) Conceive Idea

2) CAD design

3) 3d print design

4) Fill and polish printed object

5) Create Silicone Mold

6) Cast Precious Metal Clay into mold cavity

7) Fire the object in the mini kiln

Note: This process could also be adapted to use food grade silicone mold material to cast custom chocolate as well.

Table 1: Summary of Project Logistics for Silver Jewelry Maker Project

\begin{tabular}{l|l} 
Cost & Mini-kiln, silicone and ethanol $(\sim \$ 100-150)$
\end{tabular} 


\begin{tabular}{|c|c|}
\hline & PMC Clay $(\sim 50 / 16 \mathrm{~g})$ \\
\hline Time & $\begin{array}{l}\text { CAD Design } 1 \mathrm{hr} \\
\text { 3D Print } 0.5 \mathrm{hr} \\
\text { Mold Making } 0.75 \mathrm{hr} \\
\text { Cast Clay } 0.5 \mathrm{hr} \\
\text { Fire Clay in Kiln } 0.5 \mathrm{hr} \\
\text { Depending on extent of process, } 1-3 \text { Hours }\end{array}$ \\
\hline Tools/Materials & $\begin{array}{l}\text { - Small package of Smooth-On Mold Star20T silicone mixing } \\
\text { compounds } \\
\text { - Small package of PMC. We used } 16 \text { gram Sterling Silver } \\
\text { PMC3 clay by Mistusbishi motors, but other materials such } \\
\text { as copper alloy is available at a cheaper cost. } \\
\text { - Cooking oil or baby oil (to reduce PMC sticking to hands or } \\
\text { mold) } \\
\text { - Small cardboard box, or stiff card-stock paper to make a box } \\
\text { - for the mold } \\
\text { - Tape (to hold box together) } \\
\text { - Neramic mini-kiln (e.g. Mitsubishi PMC3 "Hot Pot" } \sim \$ 50) \text {, } \\
\text { - Nail/Toothpick (to put a small hole in pendant) }\end{array}$ \\
\hline Pre Requisites & $\begin{array}{l}\text { Access to 3D printer } \\
\text { Access to CAD software } \\
\text { *Alternatively, you may wish to cast regular everyday objects such } \\
\text { as buttons, gears or other trinkets to create the pendant mold for the } \\
\text { jewelry (and skip the CAD/3D printing aspects of the project) }\end{array}$ \\
\hline
\end{tabular}

\section{Lessons Learned/Tips}

Working with the Clay: PMC Clay is expensive, so efficient handling and working quickly with the clay is important to keep this project cost effective. The use of a tiny bit of oil on hands, and surfaces that the clay will touch helps reduce wasting air exposure with the clay. Also note that drops of water can be mixed on the clay to help smooth over cracks, or bond pieces together etc.

Instructions

1. Conceive an idea for pendant. 


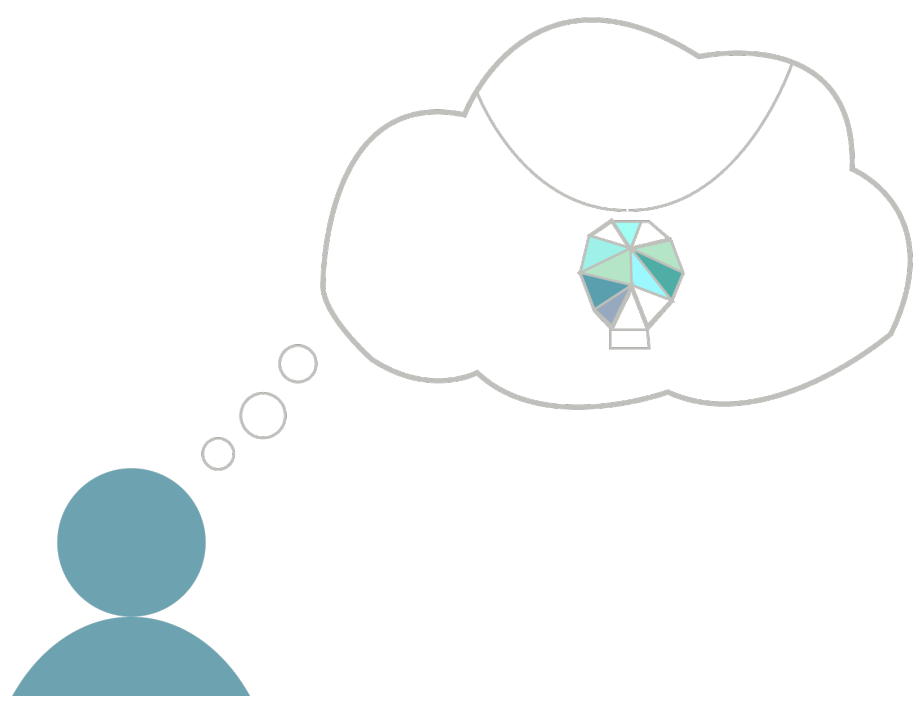

2. Create design in a CAD software. 123Dapp.com, and tinkerCAD are both free versions of $\mathrm{CAD}$ that can be used to create a jewelry pendant. Additionally Solidworks, AutoCAD, Rhino and other professional CAD software work as well. We used RhinoCAD to design a geometric meshed light bulb shape.

Export CAD file as an .stl file and send to a 3D Printer.

*Note: The object must have one flat side to it, otherwise it will require a two-part silicone mold, which has the process, explained at this site:

http://www.instructables.com/id/Two-Part-Silicone-Casting/

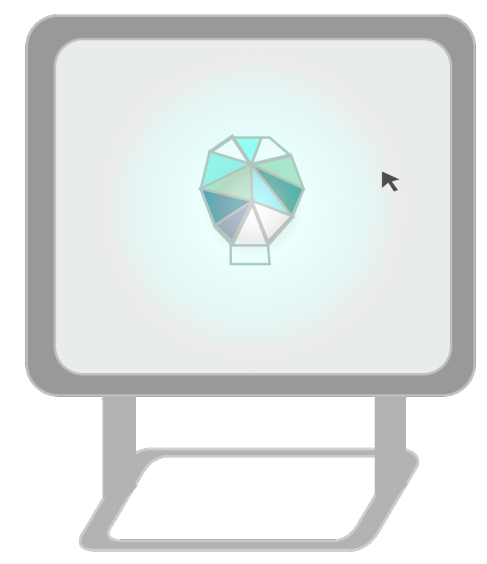


3. $3 \mathrm{D}$ print the pendant.

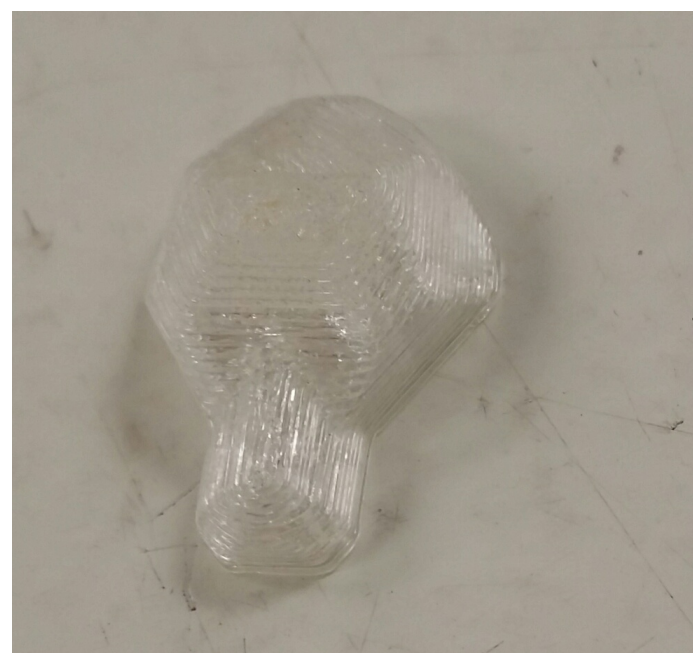

4. Fill and Polish: Fillers such as Bondo putty or XTC-3D can be used to smooth the un-even texture of a 3D print. Once dry, the putty can be polished to the desired level of smoothness.

*Note: Use caution when working with an epoxy like XTC-3D.

5. To create the silicone mold, start by finding a small packaging box in the range of 1-2 inch x 1-2 inch x 1-2 inch. A box can be created, as seen below, out of card-stock paper that is open on top and closed on the bottom. Use a small bit of glue to secure the flat end of the pendant to the bottom of the box. It is important that the flat end is at the bottom of the box and the intricate design end (or front of pendant) is facing upward from the bottom of the box. 


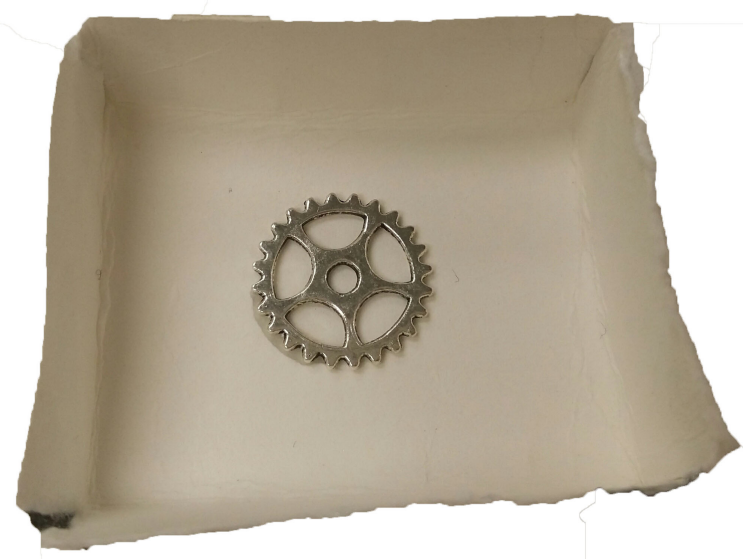

Mix the silicone molding compounds together by following the instructions on the box. We used Mold Star 20. Pour the silicone gel into the cardboard box with the pendant. Let it set and harden. Once the silicone is fully set, remove the cardboard and the pendant from the mold. Review the detail and quality of the mold. Coat the mold with a mold release or a material (like cooking oil or baby oil) to prevent PMC from sticking to the mold cavity.

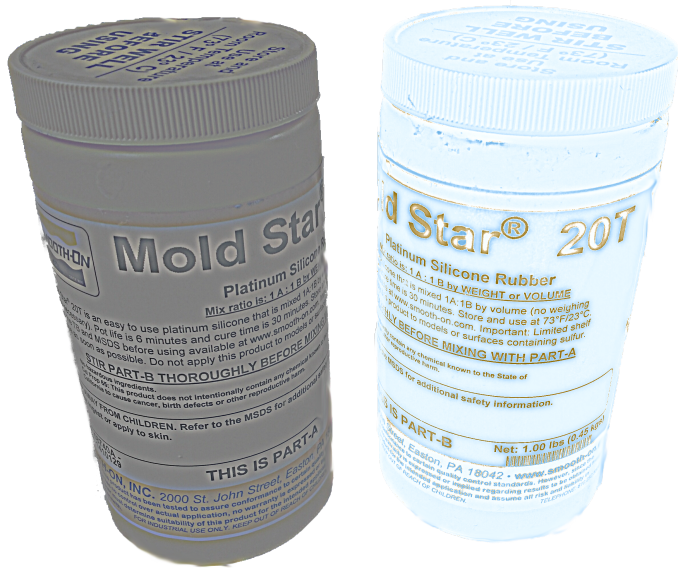



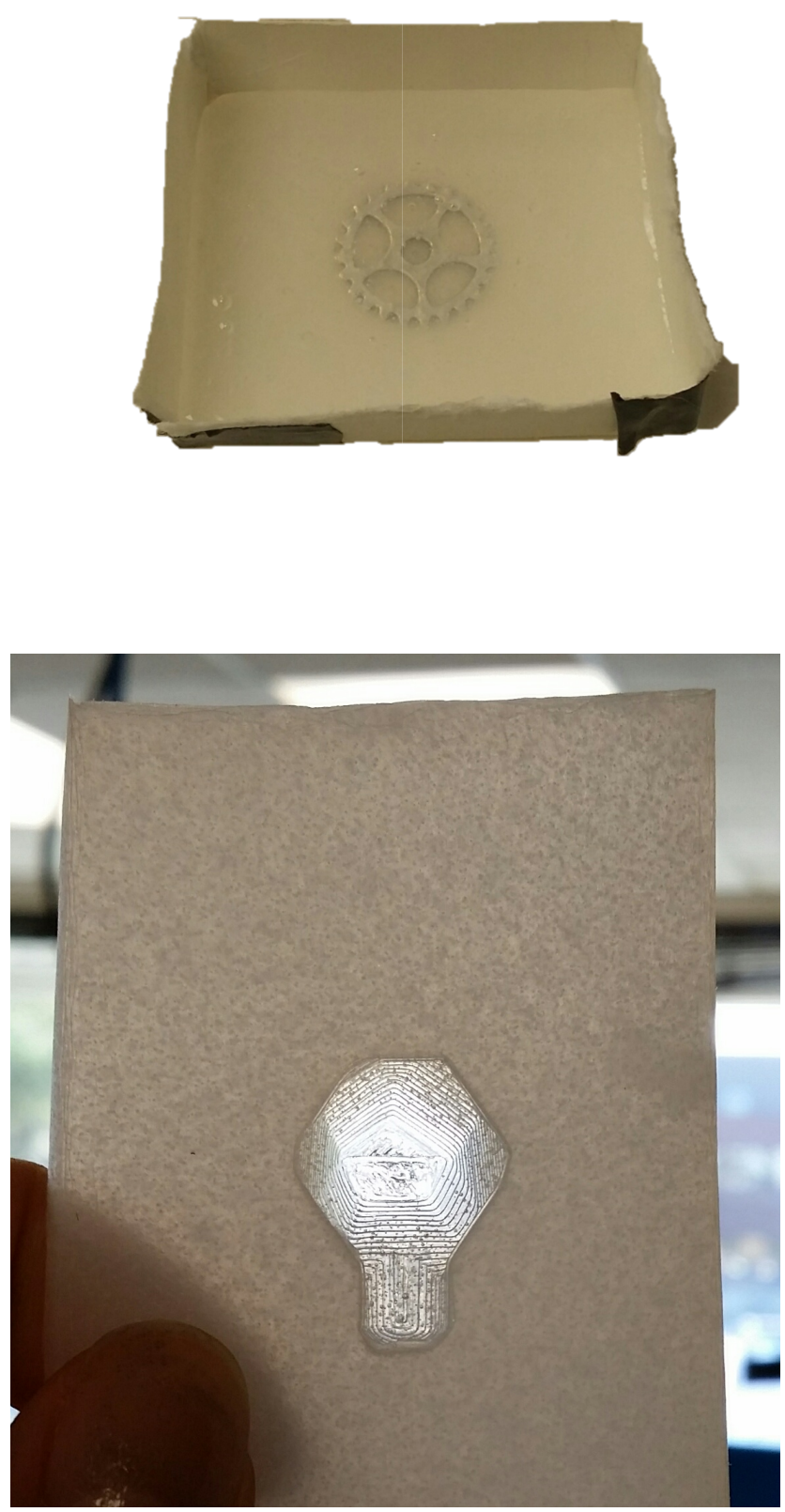

6. Cast with silver-metal clay: The PMC dries very fast and can stick to hands very easily, which makes it tricky to work with at times. It is helpful to put a little bit of oil on hands before working with the clay. It is also recommended to have everything readily available to cast the clay into the mold without delay or hassle, otherwise there is risk of the clay clumping or setting up too soon. The sooner it is put into the mold and with less handling, the better. 

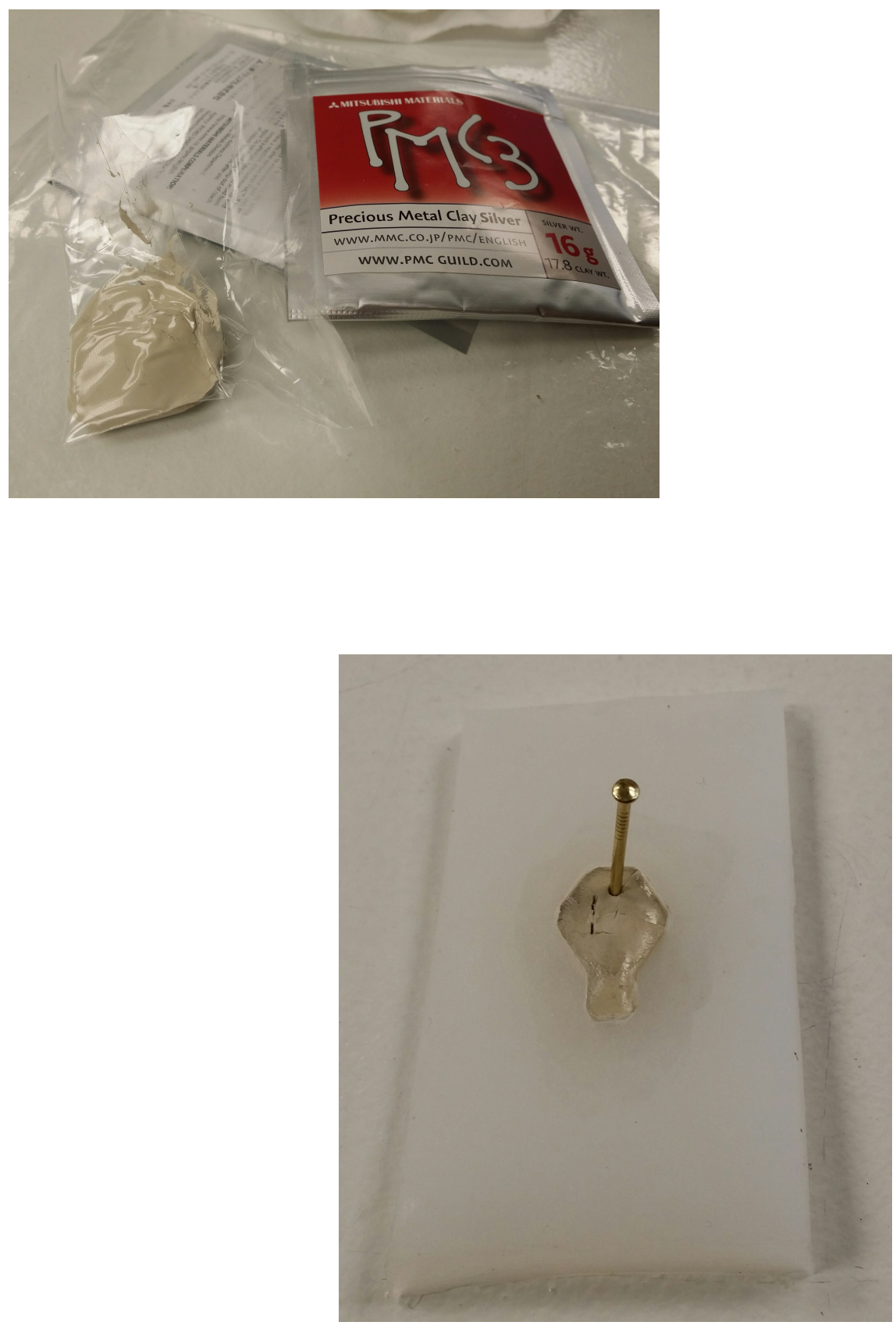

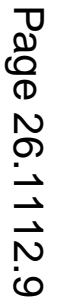


7. Poke a hole with a toothpick or nail to create an area to connect with a chain later on. Let the clay dry in the mold. Carefully take out the hardened clay from the mold. Complete any final polishing.

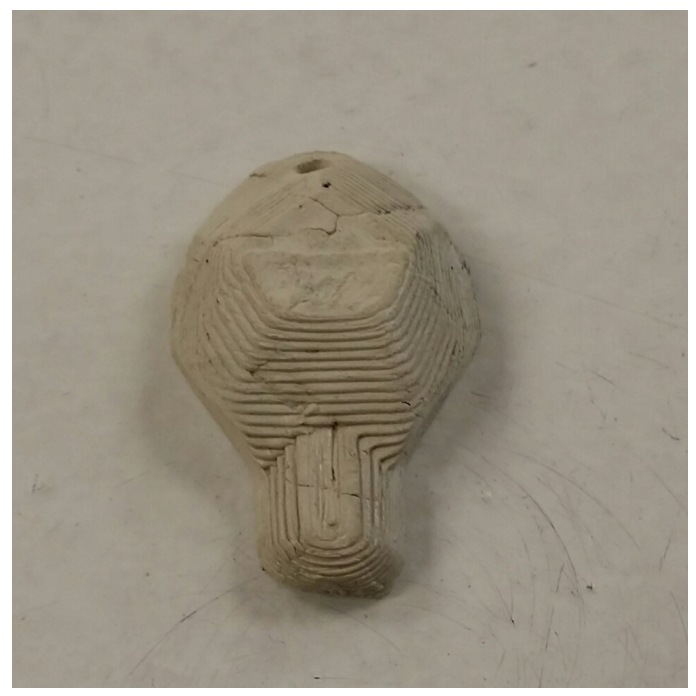

8. Fire in a mini-kiln: We used the Ecogel Ethanol Chafing Fuel, and a simplistic mini ceramic kiln (Mitsubishi PMC3 "Hot Pot" for approx. \$50). We bought both at the same jewelry store that the PMC was purchased.

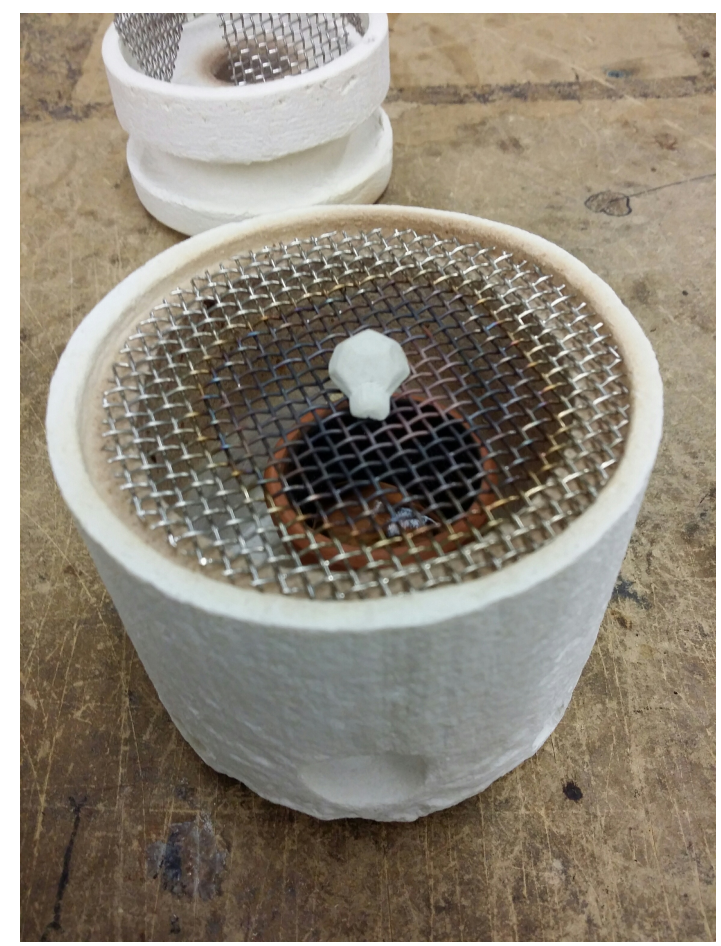


Follow the instructions on the kiln. Once firing is complete, polish the piece with a wire brush. Attach to necklace with the jewelry connector-ring or bail and the completed piece on a chain.

Final Piece
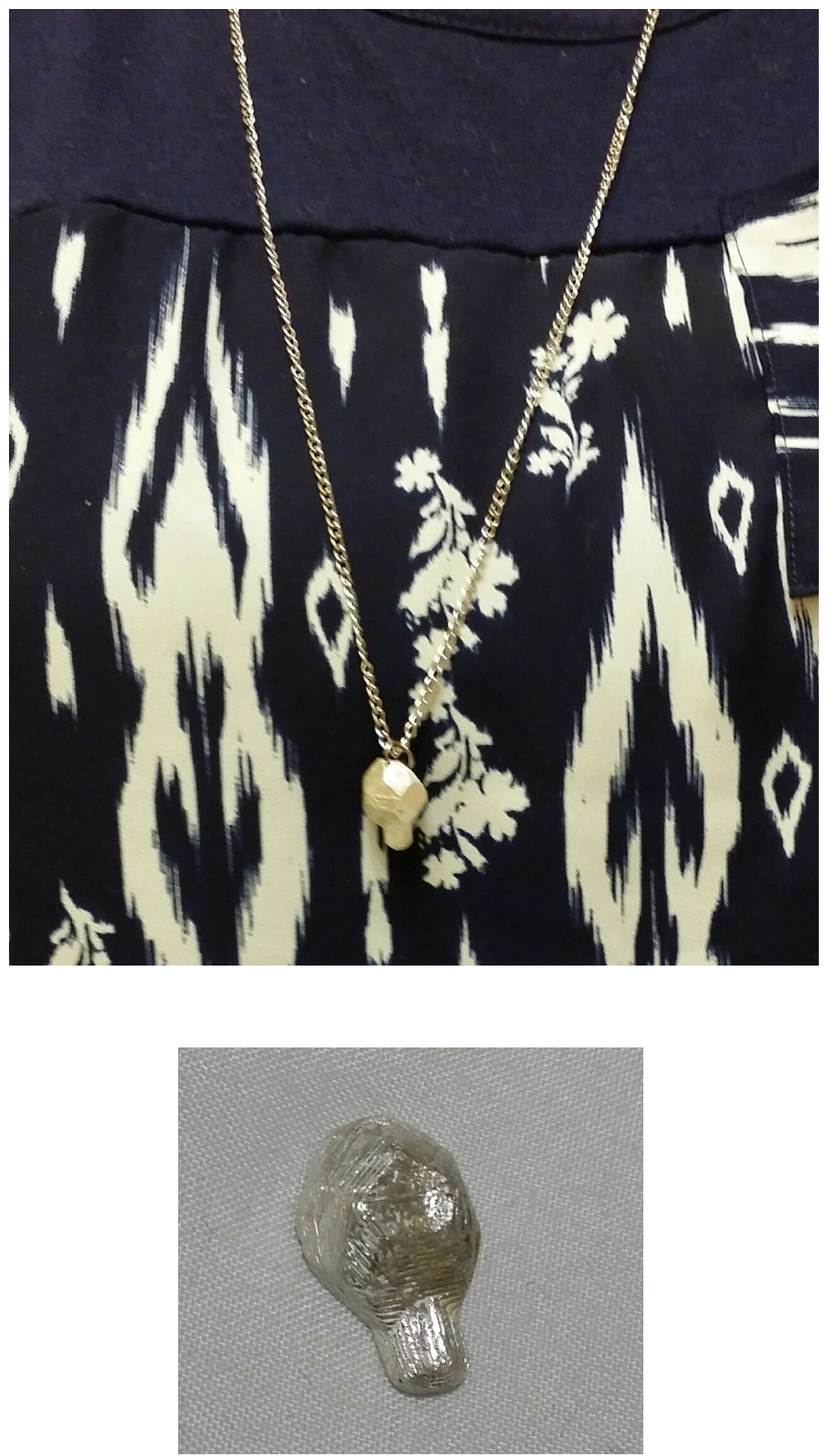

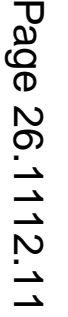




\section{References}

[1] Prince, M. J. and Felder, R. M. (2006), Inductive Teaching and Learning Methods: Definitions, Comparisons, and Research Bases. Journal of Engineering Education, 95: 123-138.

[2] Fink, L. D. (2003). Creating significant learning experiences: An integrated approach to designing college courses. San Francisco, Calif: Jossey-Bass

[3] Bransford, J.D., Brown, A.L., and Cocking, R.R., eds., How People Learn: Brain , Mind, Experience, and School, Washington, D.C.: National Academy Press, 2000. Online at $<$ http://www.nap.edu/books/0309070368/html/>. 